\title{
A Case Study Of Determinants Of An Effective Cloud Computing Strategy
}

James Lawler, Pace University, USA

Anthony Joseph, Pace University, USA

H. Howell-Barber, Pace University, USA

\begin{abstract}
The cloud continues to be an area of information systems that is being adopted cautiously by business firms. The authors of this study analyze factors that can determine the effectiveness of a cloud strategy as firms invest in this computing method. The authors examine cloud computing strategy from a detailed case study and statistical interpretation of a sample of projects of firms and organizations. The findings impute that technical factors are driving cloud computing projects more than procedural factors and that projects in the study exhibit less discipline in methodology than might otherwise be helpful in enabling an initial cloud computing strategy. This study contributes a framework for a prudent cloud computing strategy that can help firms as they further invest in this method of technology.
\end{abstract}

Keywords: Cloud; Cloud Bursting; Cloud Computing; Cloud Service Provider (CSP); Information Systems Department; Infrastructure-as-a-Service (IaaS); Platform-as-a-Service (PaaS); Software-as-a-Service (SaaS); Strategy; Virtualization

\section{BACKGROUND AND DEFINITION}

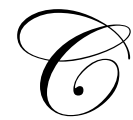

loud computing is defined in the literature as "a model for enabling convenient, on-demand network access [by business firms] to a shared pool of configurable computing resources ... that can be provisioned rapidly and released with minimal management effort or [cloud] service provider [CSP] interaction" (Walz and Grier, 2010). It is defined as a model of "pre-existing grid-style compute-and-storage [resources], tightly coupled remote compute-and-storage services that are remote, but [seem] local, and hosted computing services" (Collett, 2010). It is "the illusion of infinite computing resources available on demand, ... eliminating the need for [firms] to plan [in the] far [future] for provisioning; the elimination of an [immediate] commitment by [firms], ... allowing [firms] to ... increase hardware resources only when there is an increase in their needs; and the [inclusion of paying-as-you-go] for ... computing resources ... as needed ... and release of them as needed [by firms]" (Castro-Leon, Golden and Gomez, 2010). Cloud computing is distinguished by fast elasticity for faster scalability, increasingly on-demand resource self-service, location-independent pooling of resources, measured or metered paying for resource subscription, and ubiquitous network access to high-powered resources by firms (Walz and Grier, 2010). Cloud computing is a method for enabling more effectiveness in the existing information systems of business firms (Linthicum, January, 2010).

Cloud computing is delivered in the following models:

- Infrastructure-as-a-Service (IaaS), employed as on-demand services, such as networks, processors and storage (e.g., Amazon Web Services, GoGrid, IBM Cloud and Rackspace)

- $\quad$ Platform-as-a-Service (PaaS), employed as services, such as languages, operating systems, optimized middleware and tools (e.g., Force.Com, Google App Engine and Microsoft Windows Azure)

- $\quad$ Software-as-a-Service (SaaS), employed as paying-as-you-go services, such as applications, data and processes (e.g., Cisco WebEx, Intuit QuickBooks OnLine, Sage and SalesForce.Com) 
Of the delivery models, SaaS is the more frequent model of business firms (Wittmann, 2010), generating $\$ 12$ billion of sales for technology firms (Economist, 2011).

Benefits of the cloud are in business agility (Fogarty, August, 2010), as deployment of new products or services is enabled by a faster on-demand infrastructure, not rigid infrastructures of information systems departments (Betts, 2010). Elasticity is enabling optimized pay-as-you-go scalability of services in minutes, if not seconds, at a lower investment in over- or under-provisioning of systems (Klems, 2010). Flexibility from cloud computing is enabling a focus more on innovation than on operations of systems (Cloud Computing, 2010). Firms and organizations having limited investment in systems, but needing high-performance, are benefiting from the pooling of resources on the cloud (Weiss, 2010). The benefits of the cloud are cited frequently in the literature (Kontzer, January, 2011) and are evident in forecasts that cloud computing may be not an evolution but a revolution (West, 2010) - potentially the most profound revolution since the Internet (Hugos and Hulitzky, 2011).

\section{INTRODUCTION TO THE STUDY}

Like any hyped platform of technology, cloud computing is a concern for business firms considering expanded investment in the cloud (McCafferty, 2010). Firms are confronted by the integration of cloud and noncloud systems (Nash, 2010), the migration of non-cloud systems to private cloud infrastructures (Claybrook, August, 2010), and the interoperability performance of CSP cloud infrastructures and systems (Gartner, p.7, 2010). Lack of integration and portability standards on the cloud is a further issue (Harding, 2010 \& Schneider, 2010). Staff may not even be proficient in the integration of the systems. Though research is clear that integration of disparate systems is critical in improving initiatives of firms and organizations (Bhatt, 2000), cloud computing is not matured enough as a platform.

Literature cites concerns in cloud computing maturity. Control and security of information in public cloud, and even private cloud, infrastructures is a frequent concern in the literature (McCall, 2010), as public infrastructures are not controlled by business firms and organizations. On-demand performance and reliability are concerns as real-time planning of resource scalability may burden private and public cloud projects and systems (Castro-Leon, Golden and Gomez, 2010). Though the cloud furnishes benefits, these concerns on cloud computing may hinder investment in the platform if firms and organizations lack an initial strategy.

From the literature of practitioners, the authors of this study attempt to clarify determinants that can contribute to an effective cloud computing strategy. How are firms and organizations deploying on the cloud despite the concerns?; which cloud deployment factors and methods are consistent and effective models of projects?; and which are the right applications and projects in the right infrastructure systems? This study attempts to evaluate the effectiveness of projects and systems of business firms and organizations on the cloud, distinct from the embellishing hyperbole of technology firms (Brooks, 2010). The authors of the study define factors for a framework for projects and systems in cloud computing strategy.

\section{FACTORS IN CLOUD COMPUTING STRATEGY}

The determinants for the effectiveness of cloud computing projects and systems are defined as business, procedural and technical factors in the following framework for a cloud computing strategy. The factors are formulated largely from earlier models of the authors on service-oriented architecture (SOA) (Lawler and HowellBarber, 2008) and Web services (Lawler, Anderson, Howell-Barber, Hill and Javed and Li, 2003), inasmuch as services and SOA are considered a foundation for the cloud (Lawler, 2011) and are improved for this cloud study. These methodologies were at the forefront of innovation in 2008 and 2003 as cloud is at the forefront in 2011.

\section{Business Factors In Cloud Computing Strategy}

- $\quad$ agility benefits (Lawler, Anderson, Howell-Barber, Hill, Javed and Li, 2003) - extent to which cloud enables organization to be more agile

- $\quad$ competitive market (Lawler, Anderson, Howell-Barber, Hill, Javed and Li, 2003) - extent to which cloud enables organization to confront industry issues more effectively 
- $\quad$ cost benefits (Lawler, Anderson, Howell-Barber, Hill, Javed and Li, 2003) - extent to which cloud enables organization to deliver more financial return

- $\quad$ customer demand for improved service (Lawler, Anderson, Howell-Barber, Hill, Javed and Li, 2003) extent to which cloud enables improved service to customers

- $\quad$ executive business leadership (Lawler and Howell-Barber, 2008) - extent to which senior managers in business units evangelize cloud computing

- $\quad$ executive sponsorship (Lawler, Anderson, Howell-Barber, Hill, Javed and Li, 2003) - extent to which senior managers in organization evangelize and fund cloud computing

- $\quad$ executive technology leadership (Lawler, Anderson, Howell-Barber, Hill, Javed and Li, 2003) - extent to which senior managers in information systems department evangelize cloud computing

- $\quad$ organizational change management (Lawler and Howell-Barber, 2008) (Mendoza, Perez and Grimian, 2006) - extent to which management is evident in helping organizational staff enhance cloud computing projects

- $\quad$ participation of client organizations (Lawler, Anderson, Howell-Barber, Hill, Javed and Li, 2003) (Mendoza, Perez and Grimian, 2006) - extent to which client organizational staff participate on cloud computing projects

- $\quad$ regulatory requirements (Lawler and Howell-Barber, 2008) - extent to which cloud computing project is impacted by governmental, industrial or internal requirements

- $\quad$ strategic planning of organization (Lawler and Howell-Barber, 2008) - extent to which cloud computing is articulated as part of organizational strategy

\section{Procedural Factors In Cloud Computing Strategy}

- $\quad$ business process management (Lawler, Anderson, Howell-Barber, Hill, Javed and Li, 2003) - extent to which improvement of processes is a cloud goal

- $\quad$ candidate application selection (New to Study) - extent to which a process for cloud computing content and project selection is evident in organization

- $\quad$ change management (Lawler and Howell-Barber, 2008) (Mendoza, Perez and Grimian, 2006) - extent to which a controlled procedure is evident for ensuring optimal resolution of requests for changes in existing processes or of requests for new processes or services due to cloud computing projects

- $\quad$ cloud computing center of excellence (Lawler and Howell-Barber, 2008) (Mendoza, Perez and Grimian, 2006) - extent to which a centralized team is evident for furnishing cloud expertise to cloud computing project staff

- $\quad$ cloud planning (Mendoza, Perez and Grimian, 2006) (New to Study) - extent to which a cloud computing plan is evident before initiating cloud computing projects

- $\quad$ continuous improvement process (Lawler and Howell-Barber, 2008) - extent to which cloud computing projects are included in continuous improvement process plans

- $\quad$ costing techniques (Lawler and Howell-Barber, 2008) - extent to which costing techniques of cloud CSP technology firm(s) are easily integrated into organizational project costing techniques

- $\quad$ education and training (Lawler and Howell-Barber, 2008) (Mendoza, Perez and Grimian, 2006) - extent to which skill training on cloud computing is evident for project staff

- $\quad$ infrastructure architecture in organization (Lawler, Anderson, Howell-Barber, Hill, Javed and Li, 2003) (Mendoza, Perez and Grimian, 2006) - extent to which cloud computing projects are evident in infrastructure architecture of organization

- $\quad$ problem management (Mendoza, Perez and Grimian, 2006) (New to Study) - extent to which problem management and reporting are evident in cloud computing projects

- $\quad$ process deployment techniques (Lawler and Howell-Barber, 2008) - extent to which procedures are evident for furnishing software and tools to cross-organizational project staff

- $\quad$ program management methodology in organization (Lawler and Howell-Barber, 2008) (Mendoza, Perez and Grimian, 2006) - extent to which cloud computing projects are guided from a program management structure 
- $\quad$ project management methodology in organization (Lawler, Anderson, Howell-Barber, Hill, Javed and Li, 2003) (Mendoza, Perez and Grimian, 2006) - extent to which project management methodology is modified to a cloud computing structure

- $\quad$ responsibilities and roles (Lawler and Howell-Barber, 2008) - extent to which responsibilities and roles of cloud computing project staff are clearly identified for project tasks

- $\quad$ risk management (Lawler and Howell-Barber, 2008) - extent to which procedures are identified for mitigating failure or loss caused by cloud computing projects

- $\quad$ security management (Lawler and Howell-Barber, 2008) - extent to which procedures are identified for safeguarding access to information on cloud systems

- $\quad$ service orientation of organization (Lawler and Howell-Barber, 2008) - extent to which cloud computing project staff is receptive to principles of service-oriented architecture (SOA)

- $\quad$ standards management (Lawler, Anderson, Howell-Barber, Hill, Javed and Li, 2003) - extent to which cloud computing project staff is receptive to official standards, scope of standards of cloud CSP technology firm(s), and standards gap resolution techniques

- $\quad$ strategy management (Lawler and Howell-Barber, 2008) (Mendoza, Perez and Grimian, 2006) - extent to which procedures are evident for improving cloud computing program strategy

- $\quad$ technology firm evaluation process (New to Study) - extent to which procedures are evident for formally selecting cloud CSP technology firm(s)

\section{Technical Factors In Cloud Computing Strategy}

- $\quad$ cloud computing "bill of rights" with CSP technology firm(s) (Lawler and Howell-Barber, 2008) - extent to which a cloud "bill of rights" is evident or negotiated at CSP technology firm(s)

- $\quad$ cloud computing data model of organization (Lawler, Anderson, Howell-Barber, Hill, Javed and Li, 2003) extent to which a data, privacy and security model is evident for ensuring data integrity and quality in cloud systems

- $\quad$ cloud CSP technology firm location (Lawler and Howell-Barber, 2008) - extent to which off-shoring or onshoring of CSP technology firm(s) is evident for impact on processing of systems

- $\quad$ continuous processing (New to Study) - extent to which a procedure is evident for enabling failover of cloud computing systems

- data ownership (New to Study) - extent to which information ownership is clearly evident before implementation of cloud computing systems

- $\quad$ elasticity for faster provisioning and resource scalability (Lawler and Howell-Barber, 2008) - extent to which deployment of resource scalability is facilitated by cloud computing systems

- $\quad$ faster delivery of new application systems (Lawler and Howell-Barber, 2008) - extent to which deployment of new processing systems is facilitated by cloud technology

- $\quad$ faster delivery of new technologies (Lawler and Howell-Barber, 2008) - extent to which faster deployment of new technologies is facilitated by cloud technology

- $\quad$ integrated non-cloud application systems of organization (Lawler, Anderson, Howell-Barber, Hill, Javed and $\mathrm{Li}, 2003)$ - extent to which cloud computing systems integrate information of non-cloud systems in internal organization

- $\quad$ integrated non-cloud application systems with external organization(s) (Lawler, Anderson, Howell-Barber, Hill, Javed and $\mathrm{Li}, 2003$ ) - extent to which cloud computing systems integrate information of external noncloud systems of external organization(s)

- $\quad$ management and monitoring (New to Study) - extent to which monitoring of new systems is integrated into organizational procedures

- $\quad$ multiple cloud CSP technology firm(s) (Lawler and Howell-Barber, 2008) - extent to which multiple technology firms are involved on cloud computing systems

- $\quad$ networking technology (New to Study) - extent to which in-house networking technology is integrated on systems;non-integrated cloud application systems of organization (Lawler, Anderson, Howell-Barber, Hill, Javed and $\mathrm{Li}, 2003$ ) - extent to which cloud computing systems exist in internal organization but do not integrate into current project systems 
- $\quad$ non-integrated cloud application systems with external organization(s) (Lawler, Anderson, Howell-Barber, Hill, Javed and Li, 2003) - extent to which cloud computing systems exist in external organization(s) but do not integrate into current project systems

- $\quad$ open standards (New to Study) - extent to which non-proprietary standards are integrated in cloud computing systems

- $\quad$ platform of cloud CSP technology firm(s) (Lawler, Anderson, Howell-Barber, Hill, Javed and Li, 2003) extent to which infrastructure platform(s) of cloud CSP technology firm(s) are integrated on systems

- $\quad$ product-specific tools of cloud CSP technology firm(s) (Lawler, Anderson, Howell-Barber, Hill, Javed and $\mathrm{Li}, 2003)$ - extent to which implementation tools of CSP technology firm(s) are integrated on systems

- $\quad$ product-specific utilities of cloud CSP technology firm(s) (Lawler, Anderson, Howell-Barber, Hill, Javed and $\mathrm{Li}, 2003$ ) - extent to which run utility tools of technology firm(s) are integrated on systems

- $\quad$ proprietary technologies of cloud CSP technology firm(s) (Lawler, Anderson, Howell-Barber, Hill, Javed and Li, 2003) - extent to which proprietary tools of technology firm(s) are integrated on systems

- $\quad$ security provision of cloud CSP technology firm(s) (Lawler and Howell-Barber, 2008) - extent to which security techniques of CSP technology firm(s) are integrated on systems

- $\quad$ service level agreements with cloud CSP technology firm(s) (Lawler, Anderson, Howell-Barber, Hill, Javed and $\mathrm{Li}, 2003)$ - extent to which a service level agreement is integrated in methodology with CSP technology firm(s)

- $\quad$ service-oriented architecture (SOA) of organization (Lawler and Howell-Barber, 2008) (Mendoza, Perez and Grimian, 2006) - extent to which project is integrated in an SOA initiative

- $\quad$ standards organization membership of cloud CSP technology firm(s) (Lawler and Howell-Barber, 2008) extent to which technology firm(s) are members of Cloud Standards Coordination Initiative; standards organization membership of organization (Lawler, Anderson, Howell-Barber, Hill, Javed and Li, 2003) extent to which organization is a member of Cloud Standards Coordination Initiative

- $\quad$ technology process management of organization with cloud CSP technology firm(s) (Lawler and HowellBarber, 2008) (Mendoza, Perez and Grimian, 2006) - extent to which process management of organizational technology is integrated and provided with methodology of technology firm(s)

\section{FOCUS OF THE STUDY}

The focus of the study is to attempt to evaluate the aforementioned factors that can contribute to the effectiveness of an initial cloud computing strategy. The study contributes findings on best and non-best performance practices on cloud projects and systems that can be formulated or corrected into generic principles of strategy not frequently found in practitioner literature (Fogarty, May, 2010). The study expands scholarly findings on performance strategy for maximizing the benefits from and minimizing the concerns for technology at the forefront of practice in industry (Wang, 2010).

\section{RESEARCH METHODOLOGY}

During the period October 2011 to June 2011, the authors of this study conducted a detailed case study of the cloud computing projects and systems of three business firms and organizations investing in the cloud. The three firms and organizations were chosen by the authors because of distinguishing entrepreneurial and first mover features of the projects and systems, evident knowledge of the information systems staff on the technology, and implementation of individual private, public and hybrid cloud systems. The authors evaluated evidence of the 57 business, procedural and technical factors defined in the earlier framework of the study and implied strategy on the projects and systems in each of the three firms and organizations by a checklist instrument, from observation and perception at the firms, research at the firms, and research at other secondary sector sources. The evaluation was founded largely on principles of research (Yin, 2003). The authors applied a six-point Likert-like rating scale of 5 (very high), 4 (high), 3 (intermediate), 2 (low), 1 (very low), and 0 in perceived enablement of the factors in an initial strategy. 
ANALYSIS OF THREE FIRMS (Firms and organizations are confidentially defined in the study because of competitive considerations.)

\section{Firm 1 - Energy Research Organization}

Firm 1 is a large-sized mid-west energy research organization that focused on a delivery model of Microsoft Windows Azure as platform-as-a-service (PaaS) and a deployment model of a hybrid cloud. The goal of the project was to expand external high performance computing resources for internally generated Monte Carlo simulations and to furnish provisioning of the results of the simulations on to geo-located networks for researchers internationally. The project was to improve the performance processing of petabytes of simulations to the researchers requesting improved service and to lessen pressure on internal systems of the organization.

The business factors of agility benefits (5.00) and customer demand for improved service (5.00) were the beginning drivers of the project in Firm 1. The focus of the information systems department, however, was the technical factors of elasticity for faster provisioning of resource scalability (5.00); faster delivery of new application systems (5.00) and new technologies (5.00), integrated non-cloud systems of organizations (5.00) and with external organizations (5.00), networking technology (4.00), and platform (4.00) and tools of cloud technology firms (4.00). Governance in program management methodology in organization $(0.00)$ was non-existent and process management as a methodology was largely non-existent in business process management (0.00), organizational change management in organization (0.00), and technology process management (2.00), even though continuous improvement process (3.00) was evident on the initial project. Though executive technology leadership (5.00) was highly indicated on the project, executive business leadership (0.00) and sponsorship (0.00) were non-existent for a Firm 1 strategy. Throughout the organization, cloud computing "bill of rights" (1.00) and service level agreements with technology firms (1.00) were largely non-existent as was monitoring of costing techniques (1.00), which may hinder planned cost benefits (3.00) on the project.

Firm 1 was focused more on technical factors than on procedural and business factors in order to benefit from the faster cloud, but this method limited the benefits of a formalized governance and process strategy.

\section{Analysis Of Firm 2 - Financial Services Organization}

Firm 2 is a large-sized mid-west financial services organization that focused on models of EMC infrastructure-as-a-service (IaaS) and private cloud. The goal of the project was to improve the efficiency and flexibility of server and storage systems for internal mortgage staff and to furnish a foundation for faster growth of the systems. The project was to increase the response of the systems at notable savings.

The business factors of agility (5.00) and cost benefits (5.00) were the beginning drivers of the project. The information systems department in Firm 2, as in Firm 1, focused on the technical factors of elasticity for faster provisioning of scalability (5.00), faster delivery of new application systems (5.00), and new technologies (5.00), integrated non-cloud systems of organization (5.00) and with external organizations (5.00), and tools (5.00) and utilities of technology firms (5.00). Governance of the project was improved in program management methodology (4.00) in Firm 2, but management of the organizational process was non-existent in business process management $(0.00)$, organizational change management $(0.00)$, and technology process management (0.00), as in Firm 1. Evidence of business process frameworks, enterprise road maps and end-to-end operations was non-existent in Firms 2 and 1. The information systems department in Firm 2 led the project in executive technology leadership (5.00), as in Firm 1, and in cloud planning (4.00) and strategy management (4.00) in the data center department, but without an executive business leadership strategy (0.00) and even without participation of client departments (0.00), which, if continued in 2011-2012, may hinder the information systems department staff in learning of new opportunities in project savings. The factors of cloud computing "bill of rights" $(0.00)$ and service level agreements with technology firms (2.00) were largely not within the projects in Firms 2 and 1, as the organizations focused on tactical tasks.

Firm 2 was focused more on technical factors than on non-technical factors in order to gain project savings; but, as in Firm 1, this method might be limiting in the potential of the technology. 


\section{Analysis Of Firm 3 - Health Care Organization}

Firm 3 is a mid-sized health care organization in the northeast that focused on Amazon Elastic Computing (EC2) PaaS and public cloud as delivery and deployment models. The objective of the project in 2010 was to improve the processing of medication simulations of medical researchers. This project was to increase the processing of terabytes of simulations and to lessen pressure on in-house server systems.

The business factors of agility (5.00) and cost benefits (4.00) and customer demand for improved service (5.00) were the founding drivers of the project, as essentially in Firms 2 and 1. Firm 3 focused more on the tactical technical factors of elasticity for faster provisioning of scalability (5.00), faster delivery of new application systems (5.00) and technologies (5.00), and technologies (5.00), tools (5.00) and utilities of the technology firms (5.00), as in Firms 2 and 1. Neither program management $(0.00)$ nor even project management methodology $(0.00)$ was followed on the project in Firm 3. Risk management (0.00) and security management in the organization (0.00), as well as security provisioning of the technology shops (0.00), were especially not followed on the project in Firm 3, even though such factors are important on a public cloud. The information systems department was the leader in executive technology leadership (5.00) on the project, and as on the Firm 2 and 1 projects, the department was without a business leadership (0.00), management planning (0.00) and sponsorship strategy (0.00). Infrastructure architecture (0.00) and the responsibility of the chief architect for overall blueprinting of the technology in Firm 3 were non-existent in the organization. Responsibilities and roles of organizational staff $(0.00)$ were without a strategy. This organization, as in organizations 2 and 1 , was focused on tactical tasks that precluded strategy.

Overall, as in Table 1, Firms 3, 2 and 1 were focused more on technical tasks (means $=2.38$ ) than on procedural (1.78) and business (2.30) tasks. The goal of the firms in this case study was impacting project savings sooner from the technology, but the lack of formalized methodology and strategy might be detrimental to these firms in having further organizational savings in $2012-2015$.

Table 1: Analysis of Categorical Factors of 3 Firms from Case Study

\begin{tabular}{|l|c|c|}
\hline & Means & Standard Deviations \\
\hline Business Factors & 2.30 & 1.92 \\
\hline Procedural Factors & 1.78 & 1.50 \\
\hline Technical Factors & 2.38 & 1.77 \\
\hline
\end{tabular}

See the Appendix for analysis of the detailed factors of the study.

\section{IMPLICATIONS OF STUDY}

Even though the cloud computing projects and systems in the analysis clearly contributed benefits of convenience and efficiency to the business firms and organizations, the development was not largely enabled by a disciplined method. The implication of a lack of program management methodology is that the firms and organizations might be impacted later by the fragmentation and proliferation of incompatible cloud computing data, services and systems (Nunziata, 2010). Formalization of governance in a program management methodology is a desirable initiative.

The focus of the projects and systems was not enabled by interactions of other on-premise systems for the provisioning of services and systems in the firms and organizations. Process management was not evident on the systems of the study. The implication of a lack of process management reengineering is that the firms and organizations of the study might be impacted by a non-integrated eco-system of cloud and non-cloud on-premise systems. Process management re-engineering is a desired initiative in a cloud computing strategy.

Lastly, the analysis demonstrated that cloud computing is definitely a feasible proposition, even if not enabling strategy. Firms and organizations are investing in the cloud (Kontzer, 2011). The implication of noninvestment in the cloud is that organizations might be hindered in having productive, if not profitable, systems 
(Tabb, 2010). The importance of cloud computing as an organizational proposition, apart from the hyperbole of impact, is a criteria for initial investment (Gralla, 2010).

\section{CONCLUSION}

This study of the cloud can benefit competitive differentiation of business firms as they invest in the technology. Findings from the case study inform that technical factors of improved processing are driving projects more than procedural factors and that the projects of this study have less formality and governance methodology of planning that might otherwise facilitate an initial cloud computing strategy. More structured methodology might identify issues before they become problems. Firms and organizations might adopt cloud computing projects and systems cautiously, maximizing benefits and minimizing risks with the factors of the model defined in the study. Further scholarly study of the cloud is required in order to solidify the findings of the study. This study furnishes a foundation for future investment in cloud computing methodology and technology.

\section{AUTHOR INFORMATION}

James Lawler (Principal Author) is a professor of computer science and information systems at the Seidenberg School of Computer Science and Information Systems of Pace University in New York City. The author is a researcher in business cloud computing and entrepreneurship in the industry. E-mail: lawlerj@aol.com. Corresponding author.

Anthony Joseph is a professor of computer science and information systems at the Seidenberg School of Computer Science and Information Systems of Pace University in New York City. The author is a researcher in business cloud computing and entrepreneurship in the industry.

H. Howell-Barber is an associate executive member of the Advisory Board of the Seidenberg School. The author is a researcher in business cloud computing and entrepreneurship in the industry.

\section{REFERENCES}

1. Betts, M. (2010) Report: Cloud Information Technology (IT) Ideal for Testing Innovative Ideas. Computerworld, August 23, 5.

2. Bhatt, G.D. (2000) An Empirical Examination of the Effects of Information Systems Integration on Business Process Improvement. International Journal of Operations and Production Management, 20(11), 1331-1359.

3. Brooks, J. (2010) What is in a Cloud? eWeek, June 21, 10.

4. Castro-Leon, E., Golden, B., \& Gomez, M. (2010) Cloud Computing Basics. SOA Magazine, December, 1, 3.

5. Collett, S. (2010) The Cloud Enigma: Is Cloud Computing the Next Best Thing in Information Technology (IT), or Is It Over-Hyped and Under-Delivering? Computerworld, January 4, 22.

6. Fogarty, K. (2010) When Integrating Cloud Applications, Stay Focused on Users. CIO, May 15, 28.

7. Fogarty, K. (2010) Which Applications Should You Move to the Cloud? 5 Guidelines. CIO, August 18, 2.

8. Gralla, P. (2010) Your New Information Technology (IT) Job: Twittering in the Cloud? Computerworld, December 20, 16.

9. Harding, C. (2010) Standards for a Better Cloud. Baseline, September / October, 28.

10. Hugos, M., \& Hulitzky, D. (2011) Business in the Cloud: What Every Business Needs to Know about Cloud Computing. John Wiley \& Sons, Inc., Hoboken, New Jersey, 38.

11. Klems, M. (2010) Twenty-One Experts Define Cloud Computing. Cloud Computing Journal, November, 1.

12. Kontzer, T. (2011) Cloud Forecast 2015. CIO Insight, January 7, 1-4.

13. Kontzer, T. (2011) Your Cloud Checklist for 2015. CIO Insight, January 7, 1-4.

14. Lawler, J.P. (2011) Cloud Computing in the Curricula of Schools of Computer Science and Information Systems. Information Systems Education Journal, 27(1313), 1-20. 
15. Lawler, J.P., Anderson, D., Howell-Barber, H., Hill, J., Javed, N., \& Li, Z. (2003) A Study of Web Services Strategy in the Financial Services Industry. Information Systems Education Journal, 3(3), 1-25.

16. Lawler, J.P., \& Howell-Barber, H. (2008) Service-Oriented Architecture: SOA Strategy, Methodology and Technology. Taylor \& Francis Group, Boca Raton, Florida, 45-49.

17. Lawler, J.P., \& Howell-Barber, H. (2010) A Foundation for Cloud Computing in Computer Science Curriculum.

18. Proceedings of the Northeast Business and Economics Association (NBEA) Conference, Morristown, New Jersey, October 1.

19. Linthicum, D. (2010) Why Chief Information Officers (CIOs) Should Give the Cloud a Chance. Infoworld, January 7,1 .

20. McCall, M. (2010) Cloud Spreads through Enterprise. IEEE Computer, December 18, 1-2.

21. Mendoza, L., Perez, L., \& Grimian, A. (2006) Critical Success Factors for Managing Systems Integration. Information Systems Management, 23(2), 56-75.

22. Nash, K. (2010) Clash of the Clouds: No Standards Vendor Lock-In. Uptime Uncertainity. Confusion Reigns When Integrating Cloud Technologies. CIO, May 15, 24.

23. Nunziata, S. (2010) News Slideshow: Information Governance Strategies in the Cloud. CIO Insight, November 22, 1-2.

24. Schneider, I. (2010) Top 10 Cloud Computing Complaints. Wall Street \& Technology, August 23, 1-5.

25. Tabb, L. (2010). Companies that Ignore Cloud Computing Could Be Left for Dead. Wall Street \& Technology, November 23, 1-6.

26. Walz, J., \& Grier, D.A. (2010) Time to Push the Cloud. IEEE IT Pro, September / October, 14.

27. Wang, P. (2010) Chasing the Hottest Information Technology: Effects of Information Technology Fashion on Organizations. MIS Quarterly, 34(1), 63-83.

28. Weiss, T.R. (2010) Supercomputing Grows in the Cloud. Computerworld, August 9, 7.

29. West, D.M. (2010) Saving Money through Cloud Computing. Governance Studies at Brookings, April 7, 1.

30. Yin, R.K. (2003) Applications of Case Study Research, Second Edition. Sage Publications, Inc., Applied Social Research Methods Series, (34), Thousand Oaks, California.

31. _ (2010) Make the Cloud Work for You. Cloud Computing, November 16, 1-4.

32. (2010) Gartner Global Information Technology (IT) Council for Cloud Services. Gartner, 7.

33. (2011) Tanks in the Cloud: Computing Services Are Both Bigger and Smaller Than Assumed. The Economist, January 1, 49-50. 

APPENDIX

\begin{tabular}{|c|c|c|c|c|c|}
\hline \multicolumn{6}{|c|}{ Analysis of Detailed Factors of 3 Firms from Case Study } \\
\hline Business Factors & Firm 1 & Firm 2 & Firm 3 & Summary & Summary \\
\hline & Means & Means & Means & Means & $\begin{array}{c}\text { Standard } \\
\text { Deviations }\end{array}$ \\
\hline Agility Benefits & 5.00 & 5.00 & 5.00 & 5.00 & 0.00 \\
\hline Competitive Market & 0.00 & 4.00 & 0.00 & 1.33 & 2.31 \\
\hline Cost Benefits & 3.00 & 5.00 & 4.00 & 4.00 & 1.00 \\
\hline Customer Demand for Improved Service & 5.00 & 0.00 & 5.00 & 3.33 & 2.89 \\
\hline Executive Business Leadership & 0.00 & 0.00 & 0.00 & 0.00 & 0.00 \\
\hline Executive Sponsorship & 0.00 & 0.00 & 0.00 & 0.00 & 0.00 \\
\hline Executive Technology Leadership & 5.00 & 5.00 & 5.00 & 5.00 & 0.00 \\
\hline Organizational Change Management & 0.00 & 0.00 & 0.00 & 0.00 & 0.00 \\
\hline Participation of Client Organizations & 4.00 & 0.00 & 5.00 & 3.00 & 2.65 \\
\hline Regulatory Requirements & 0.00 & 4.00 & 0.00 & 1.33 & 2.31 \\
\hline Strategic Planning of Organization & 3.00 & 4.00 & 0.00 & 2.33 & 2.08 \\
\hline
\end{tabular}

\begin{tabular}{|c|c|c|c|c|c|}
\hline Procedural Factors & Firm 1 & Firm 2 & Firm 3 & Summary & Summary \\
\hline & Means & Means & Means & Means & $\begin{array}{r}\text { Standard } \\
\text { Deviations }\end{array}$ \\
\hline Business Process Management & 0.00 & 0.00 & 0.00 & 0.00 & 0.00 \\
\hline Candidate Application Selection & 4.00 & 4.00 & 4.00 & 4.00 & 0.00 \\
\hline Change Management & 2.00 & 2.00 & 3.00 & 2.33 & 0.58 \\
\hline Cloud Computing Center of Excellence & 4.00 & 3.00 & 3.00 & 3.33 & 0.58 \\
\hline Cloud Planning & 3.00 & 4.00 & 2.00 & 3.00 & 1.00 \\
\hline Continuous Improvement Process & 3.00 & 3.00 & 3.00 & 3.00 & 0.00 \\
\hline Costing Techniques & 1.00 & 5.00 & 5.00 & 3.67 & 2.31 \\
\hline Education and Training & 0.00 & 0.00 & 0.00 & 0.00 & 0.00 \\
\hline Infrastructure Architecture in Organization & 3.00 & 4.00 & 0.00 & 2.33 & 2.08 \\
\hline Problem Management & 0.00 & 3.00 & 5.00 & 2.67 & 2.52 \\
\hline Process Deployment Techniques & 0.00 & 0.00 & 0.00 & 0.00 & 0.00 \\
\hline $\begin{array}{l}\text { Program Management Methodology in } \\
\text { Organization }\end{array}$ & 0.00 & 4.00 & 0.00 & 1.33 & 2.31 \\
\hline $\begin{array}{l}\text { Project Management Methodology in } \\
\text { Organization }\end{array}$ & 2.00 & 0.00 & 0.00 & 0.67 & 1.15 \\
\hline Responsibilities and Roles & 0.00 & 0.00 & 0.00 & 0.00 & 0.00 \\
\hline Risk Management & 2.00 & 4.00 & 0.00 & 2.00 & 2.00 \\
\hline Security Management & 1.00 & 4.00 & 0.00 & 1.67 & 2.08 \\
\hline Service Orientation of Organization & 0.00 & 0.00 & 0.00 & 0.00 & 0.00 \\
\hline Standards Management & 0.00 & 0.00 & 0.00 & 0.00 & 0.00 \\
\hline Strategy Management & 0.00 & 4.00 & 0.00 & 1.33 & 2.31 \\
\hline Technology Firm Evaluation Process & 5.00 & 3.00 & 5.00 & 4.33 & 1.15 \\
\hline
\end{tabular}




\begin{tabular}{|c|c|c|c|c|c|}
\hline Technical Factors & Firm 1 & Firm 2 & Firm 3 & Summary & Summary \\
\hline & Means & Means & Means & Means & $\begin{array}{c}\text { Standard } \\
\text { Deviations }\end{array}$ \\
\hline $\begin{array}{l}\text { Cloud Computing "Bill of Rights" with } \\
\text { CSP Technology Firm(s) }\end{array}$ & 1.00 & 0.00 & 0.00 & 0.33 & 0.58 \\
\hline $\begin{array}{l}\text { Cloud Computing Data Model of } \\
\text { Organization }\end{array}$ & 1.00 & 4.00 & 0.00 & 1.67 & 2.08 \\
\hline Cloud CSP Technology Firm Location & 0.00 & 3.00 & 0.00 & 1.00 & 1.73 \\
\hline Continuous Processing & 0.00 & 5.00 & 0.00 & 1.67 & 2.89 \\
\hline Data Ownership & 4.00 & 5.00 & 5.00 & 4.67 & 0.58 \\
\hline $\begin{array}{l}\text { Elasticity for Faster Provisioning and } \\
\text { Resource Scalability }\end{array}$ & 5.00 & 5.00 & 5.00 & 5.00 & 0.00 \\
\hline $\begin{array}{l}\text { Faster Delivery of New Application } \\
\text { Systems }\end{array}$ & 5.00 & 5.00 & 5.00 & 5.00 & 0.00 \\
\hline Faster Delivery of New Technologies & 5.00 & 5.00 & 5.00 & 5.00 & 0.00 \\
\hline $\begin{array}{l}\text { Integrated Non-Cloud Application Systems } \\
\text { of Organization }\end{array}$ & 5.00 & 5.00 & 0.00 & 3.33 & 2.89 \\
\hline $\begin{array}{l}\text { Integrated Non-Cloud Application Systems } \\
\text { with External Organization(s) }\end{array}$ & 5.00 & 5.00 & 0.00 & 3.33 & 2.89 \\
\hline Management and Monitoring & 4.00 & 5.00 & 5.00 & 4.67 & 0.58 \\
\hline Multiple Cloud CSP Technology Firm(s) & 5.00 & 4.00 & 0.00 & 3.00 & 2.65 \\
\hline Networking Technology & 4.00 & 4.00 & 0.00 & 2.67 & 2.31 \\
\hline $\begin{array}{l}\text { Non-Integrated Cloud Application Systems } \\
\text { of Organization }\end{array}$ & 0.00 & 4.00 & 0.00 & 1.33 & 2.31 \\
\hline $\begin{array}{l}\text { Non-Integrated Cloud Application Systems } \\
\text { with External Organizations }\end{array}$ & 0.00 & 4.00 & 0.00 & 1.33 & 2.31 \\
\hline Open Standards & 0.00 & 0.00 & 0.00 & 0.00 & 0.00 \\
\hline $\begin{array}{l}\text { Platform of Cloud CSP Technology } \\
\text { Firm(s) }\end{array}$ & 4.00 & 0.00 & 5.00 & 3.00 & 2.65 \\
\hline $\begin{array}{l}\text { Product-Specific Tools of Cloud CSP } \\
\text { Technology Firm(s) }\end{array}$ & 4.00 & 5.00 & 5.00 & 4.67 & 0.58 \\
\hline $\begin{array}{l}\text { Product-Specific Utilities of Cloud CSP } \\
\text { Technology Firm(s) }\end{array}$ & 2.00 & 5.00 & 5.00 & 4.00 & 1.73 \\
\hline $\begin{array}{l}\text { Proprietary Technologies of Cloud CSP } \\
\text { Technology Firm(s) }\end{array}$ & 1.00 & 5.00 & 0.00 & 2.00 & 2.65 \\
\hline $\begin{array}{l}\text { Security Provision of Cloud CSP } \\
\text { Technology Firm(s) }\end{array}$ & 1.00 & 2.00 & 0.00 & 1.00 & 1.00 \\
\hline $\begin{array}{l}\text { Service Level Agreements with Cloud CSP } \\
\text { Technology Firm(s) }\end{array}$ & 1.00 & 2.00 & 5.00 & 2.67 & 2.08 \\
\hline $\begin{array}{l}\text { Service-Oriented Architecture (SOA) of } \\
\text { Organization }\end{array}$ & 0.00 & 0.00 & 0.00 & 0.00 & 0.00 \\
\hline $\begin{array}{l}\text { Standards Organization Membership of } \\
\text { Cloud CSP Technology Firm(s) }\end{array}$ & 0.00 & 0.00 & 0.00 & 0.00 & 0.00 \\
\hline $\begin{array}{l}\text { Standards Organization Membership of } \\
\text { Organization }\end{array}$ & 0.00 & 0.00 & 0.00 & 0.00 & 0.00 \\
\hline $\begin{array}{l}\text { Technology Process Management of } \\
\text { Organization with Cloud CSP Technology } \\
\text { Firm(s) }\end{array}$ & 2.00 & 0.00 & 0.00 & 0.67 & 1.15 \\
\hline
\end{tabular}


NOTES 